\title{
- Chronic Fluorosis: A Disease of Concern
}

\section{Mendez DC ${ }^{1}$, Shashidhar KN ${ }^{2}$}

\section{IJCRR}

Section: Healthcare ISI Impact Factor (2019-20): 1.628

IC Value (2019): 90.81 SJIF $(2020)=7.893$

(c) (7) (8)
'Ph.D, Assistant Professor, Department of Biochemistry, Sri Devaraj Urs Medical College, A Constituent College of Sri Devaraj Urs Academy of Higher Education and Research, Tamaka, Kolar, Karnataka-563103, India; ${ }^{2}$ M.D., Professor, Department of Biochemistry, Sri Devaraj Urs Medical College, A Constituent College of Sri Devaraj Urs Academy of Higher Education and Research, Tamaka, Kolar, Karnataka-563103, India.

\section{ABSTRACT}

Introduction: Chronic fluorosis is a widespread disease caused by ingestion of high levels of fluoride through drinking water and food. Fluoride content in food depends on its concentration in water, soil and air.

Aim: This review article is aimed at providing information about fluorosis and its ill effects.

Objective: The objective is to address the adverse effect of fluoride on several organ systems besides the more commonly known skeletal and dental manifestations.

Methodology: A detailed search of related literature has been carried out with the help of search engines. Pub Med and Research gate have been used for obtaining authentic information.

Discussion and Conclusion: This review article summarizes the major deleterious health problems caused by fluoride and emphasizes that fluoride mitigation needs to be practised widely since fluorosis is a preventable disorder.

Key Words: Fluoride, Fluorosis, Toxic effects, Diabetes, Thyroid abnormalities, Cardiovascular system

\section{INTRODUCTION}

The $13^{\text {th }}$ most abundant element in the earth's crust is Fluorine. ${ }^{1}$ It is only a microelement for human health but is one of the most significant endotoxins which appear in the environment. ${ }^{2}$ Fluoride is one of the few elements that have been shown to cause significant effects by various means such as through drinking water, air, dental products, food and beverages. Excessive fluoride in water and soil is mostly of geological origin which can be further compounded by over-exploitation of groundwater resources and Industrial pollutants.

After absorption from the gastrointestinal tract (GIT), the ability of fluoride ions to easily penetrate the cells through the membrane results in affecting various functions by altering the activity of enzymes and hormones. ${ }^{3,4}$ Fluoride not only accumulates in the bones and teeth but also gets deposited in the soft tissues. ${ }^{5}$ The level of fluoride, considered safe for humans is $1-1.5 \mathrm{mg} / \mathrm{L}$ while, prolonged ingestion is associated with dental fluorosis, skeletal fluorosis and several other disorders due to its ability to inhibit the proliferation of cells. It should be noted, however, that whileMicromolar Fluoride ion concentrations promote the growth and proliferation of cells, millimolar concentrations suppress cell proliferation and induce apoptosis in the hard tissues. ${ }^{6-9]}$. Many metals such as lead, copper and manganese can interact with Fluoride ion and contribute to increased accumulation of toxic elements and micronutrient deficiency in mammals. ${ }^{10,11}$

\section{Effect on bones and teeth}

Fluoride has proved to be highly effective in the prevention of dental caries. It gives long-lasting protection against dental decay. Regular fluoride exposure at the time of teeth development contributes to protection against dental decay. Plaque bacteria form organic acids, which dissociate releasing $\mathrm{H}^{+}$ions and lower the $\mathrm{pH}$ in areas surrounding the tooth and finally leads to the release of calcium from the tooth. ${ }^{12}$ Fluoride inhibits this demineralization and thus has a dental caries protection potential. Fluoride also has an antimicrobial effect as it inhibits carbohydrate metabolism in oral streptococci and lactobacilli as it inhibits the enzymes enolase and adenosine triphosphatase. ${ }^{13,14}$ Though, it has

\section{Corresponding Author:}

Dr. Deena Mendez, Department of Biochemistry, Sri Devaraj Urs Medical College, Constituent institute of Sri Devaraj Urs Academy of Higher Education and Research, Kolar, Karnataka - 563103; Phone: +91 9663085990; Email: deenaharper@gmail.com

ISSN: 2231-2196 (Print) ISSN: 0975-5241 (Online)

Received: $13.01 .2021 \quad$ Revised: 09.02 .2021

Accepted: 12.04 .2021

Published: 12.09 .2021 
beneficial effects on teeth and bones when present in low concentrations, excessive intake gives rise to adverse effects from dental fluorosis to the crippling skeletal fluorosis depending on the level of fluoride and the period of exposure. As the fluoride ion is strongly electronegative, it is attracted to the positively charged $\mathrm{Ca}$ ions in the teeth and bones. ${ }^{15}$ Fluoride alters the resorption of bone tissue and affects the homeostasis of bone mineral metabolism. Fluoride ion reacts with crystals of hydroxyapatite and forms a scaffold for the bones. A combination of osteosclerosis, osteomalacia and osteoporosis in varying degrees characterizes the bone lesions. ${ }^{16}$

The high affinity of Fluoride ion to mineralized tissues results in the high Fluoride ion concentrations in bones and teeth and so these materials are used as a bioindication of long term exposure to Fluoride. ${ }^{17,18}$ the earliest sign of chronic fluoride exposure is the characteristic mottling of dental enamel.

\section{Effect on Thyroid Function}

Excessive amounts of Fluoride interfere with the functioning of the thyroid gland. The thyroid gland is the most sensitive organ to the effect of fluoride. ${ }^{19}$

Since fluoride is more electronegative than iodine, it easily displaces iodine and thus affects the functioning of the thyroid gland. It is regulated by a negative feedback mechanism i.e. when the pituitary gland senses a drop in $\mathrm{F} \mathrm{T}_{3}$ levels in circulations; it releases more TSH which stimulates the thyroid gland to accelerate the production of $\mathrm{T}_{4}$. The Source of $\mathrm{T}_{3}$ is from peripheral deiodination of $\mathrm{T}_{4}$. The enzymes which bring about deiodination are known asiodothyroninedeiodinases and fluoride interfere with the activity of the deiodinases. ${ }^{20,21}$ Thus, Fluoride increases the concentration of $\mathrm{TSH}$ and decreases the concentration of $\mathrm{T}_{3}$ and $\mathrm{T}_{4}$ hormones.

Effect on thyroid function was associated with a fluoride exposure level of $0.05-0.13 \mathrm{mg} / \mathrm{kg} /$ day when iodine intake was adequate and $0.01-0.03 \mathrm{mg} / \mathrm{kg} /$ day when iodine intake was inadequate..$^{22}$

\section{Effect on melatonin production}

Animal studies on the effect of fluoride exposure to pineal glands show that it results in altered melatonin production and acceleration of sexual maturity. The reduced Melatonin production can impair the sleep-wake cycle. However, no studies on humans have been demonstrated. ${ }^{23,24}$

\section{Effects on Insulin secretion and Diabetes}

Various studies have shown that insulin resistance in humans develops due to chronic fluoride exposure. ${ }^{23,24}$ Impaired glucose metabolism is associated with a serum fluoride concentration of 0.1 ppm or greater. ${ }^{25,26}$ Hyperglycemia induced by fluoride is mainly due to an increase in hepatic glycogenoly- sis. ${ }^{27}$ Fluoride inhibits the glycolytic pathway by inhibiting enolase resulting in increased accumulation of two phosphoglycerates which is equilibrated by three phosphoglycerate enzymes being phosphoglucomutase. As a result, blood glucose levels increase. ${ }^{28}$ Moreover, diabetic patients tend to consume larger quantities of water and this further leads to fluoride accumulation. ${ }^{29}$ This in turn leads to impaired renal function, increased capillary permeability and microcirculatory defects. ${ }^{30,31}$ Invitro experiments on isolated Islets of Langerhans cells showed that the basal, as well as glucosestimulated insulin, was found to be repressed as the fluoride concentration was increased..$^{31}$

\section{Fetal defects}

Fluoride can cross the placental barrier into fetal tissue. It can affect the fetal brain tissue and this can cause neurological damage, neuronal degeneration and reduced secretion of norepinephrine. Fluoride also disrupts nerve cell receptors which can result in neural dysplasia. ${ }^{32}$ Fluoride has been found in the amniotic fluid in pregnant women living in areas of high fluoride concentrations and this result in fetuses being exposed to elevated fluoride levels. ${ }^{33}$

In mammalian cells, fluoride causes genetic damage through chromosomal aberrations at cytotoxic concentrations $(\geq 10$ $\mathrm{mg} / \mathrm{L}$ ) which may be due to the interaction of enzymes responsible for DNA synthesis or repair. ${ }^{34}$

\section{Effect on brain}

A few epidemiological studies have shown lowered IQ levels in children exposed to 2.5 to $4 \mathrm{mg} / \mathrm{L}$ of fluoride in drinking water. ${ }^{35}$ Fluoride also tends to increase free radical production in the brain which may have a bearing in increasing the risk of developing Alzheimer's disease and dementia. ${ }^{22,36}$ Experiments on mice have shown that chronic exposure to Fluoride brings about changes in learning, memory as well as neuropathological injury. It also raised the number of senile plaque, decreased levels of synaptic proteins and caused inflammation in the brain. This in turn could lead to an increased risk. $^{37}$

\section{Effect on Reproductive health}

Lowered fertility rates have been implicated with increased fluoride levels as prolonged fluoride exposure is associated with increased levels of follicle-stimulating hormone (FSH) and luteinizing hormone ( $\mathrm{LH}$ ) and brings about decreased estrogen levels. ${ }^{38-40}$

Prolonged exposure to fluoride also leads to decreased testosterone levels and delay in its conversion to potent metabolites, disturbed androgen to estrogen rations as well as estrogen receptor to androgen receptor ratios. ${ }^{40}$ This effect on reproductive health is further compounded due to reduced thyroid hormones. ${ }^{41,42}$ 


\section{Haematological effects}

Chronic fluoride exposure brings about haematological effects such as anaemia, eosinophilia and dysplastic changes on granulocytes in the bone marrow. ${ }^{43}$ Fluoride is also known to destroy probiotics in the gut, resulting in decreased production of Vitamin B12 which is required for Hemoglobin synthesis. ${ }^{44}$

\section{Effect on Renal system}

The kidney has a major role to play in the excretion of fluoride and the kidney tubules are also damaged due to uptake of fluoride.$^{45}$ Prolonged exposure to high levels of fluoride increases the probability of developing renal diseases due to the structural and functional changes in the kidney such as swelling, degeneration of tubular epithelium, fibrosis and tubular necrosis. This in turn leads to increased serum creatinine and urea nitrogen. ${ }^{46}$

\section{Effects on Gastrointestinal tract (GIT)}

High concentrations of fluoride react with hydrochloric acid in the stomach to form hydrogen fluoride. The excessive formation of hydrofluoric acid results in irritation of the gastric mucosa. ${ }^{47}$ As, Fluoride also stimulates secretion of gastric acid this, will diminish the blood supply in the stomach lining, resulting in death of epithelial cells in the GIT. Though, this observation has not been well documented in humans, adverse GIT symptoms are seen in areas of endemic fluorosis especially when the quality of nutrition is poor. ${ }^{48}$

\section{Central Nervous System}

Fluoride can cross the blood-brain barrier before birth and is believed to affect mental development. This can result in learning disorders and decreased intelligence in children. Reports of decreased levels of neurotransmitters have been seen in fluoride endemic areas. ${ }^{49}$

Fluoride brings about degenerative changes in the neural tissue which can lead to decreased memory and learning ability. ${ }^{46}$ The effect may be further compounded by deficiency of some elements such as iodine or the presence of other neurotoxic compounds as pollutants. ${ }^{49}$

\section{Effect on Immunity}

Chronic fluoride exposure affects cell-mediated and humoral immunity as it destroys white blood cell energy reservoirs thus affecting phagocytosis and inhibition of antibody formation. ${ }^{46}$

\section{Effect on Reproductive system}

The effect of fluoride on the reproduction system has not been investigated in detail though fluoride was indicted for decreased birth rates. ${ }^{50}$ In one study, an interesting observation was that organic farmers who avoided pesticides were found to have double the average sperm density when compared to other farmers who used pesticides treated with fluoride. ${ }^{51} \mathrm{High}$ Fluoride levels are also known to be associated with reduced Testosterone levels..$^{52}$

\section{Effect on Cardiovascular system}

Chronic fluoride exposure promotes inflammatory mechanisms. This in turn can lead to atherosclerosis and myocardial cell damage as oxidative stress, along with inflammation are important mechanisms involved in ischemic stroke. Fluoride also interferes with numerous enzymes resulting in elevating the risk factors for cardiovascular diseases besides, causing degeneration of the heart muscle. ${ }^{53-55}$ ECG of patients with dental fluorosis showed that a significant percentage of them had abnormal heart rhythms. ${ }^{56,57}$

\section{Anaesthetic concerns in chronic fluorosis}

In patients with fluorosis, there may be difficulty in intubation during anaesthesia due to the rigid cervical spine which is compounded with the limitation of movements of the intervertebral joints. ${ }^{58,59}$ There is also a greater degree of risk for postoperative respiratory complications due to restricted chest movement. ${ }^{58-60}$

\section{CONCLUSION}

Though fluorosis is a preventable disorder, it is unfortunately linked to several abnormalities which require attention. The various linked disorders of fluorosis need to be addressed. Combating fluorosis can be achieved by bringing about awareness, motivating and disseminating knowledge to the public on the avoidance of fluoride contaminated drinking water, arrangements of alternate sources of water, provision of fluoride-free drinking water, improving nutritional status and health education. Though some progress has been made, there is still a lot left to do. This review article is an attempt to disseminate information among medical practitioners and public health specialists.

\section{ACKNOWLEDGEMENTS}

We gratefully acknowledge the scholars and scientists who have worked in the field of fluoride research and whose articles we have cited and included as references.

\section{Conflict of interest}

The authors declare that there is no conflict of interest.

Source of funding - Nil

\section{REFERENCES}

1. Paasivarta J. Long term effects of bioaccumulation in ecosystems. In: Beck B editor.The handbook of Environment Chemistry.Berlin: Springer Publication;2000.p201-33. 
2. Arlappa N, Aatif IQ, Srinivas R. Fluorosis in India: An overview. Int J Res Dev Health. 2013; 1: 97-102.

3. Birknew E, Mamczar EG, Kasperczyk S, Kasperczyk A, Pieta BS, Fiolka JZ et al. The influence of fluoride ions upon selected enzymes of protein metabolism in the blood plasma of rabbits with hypercholesterolemia.Biological Trace Elements Research2008; 124: 118-28.

4. Wu C, Gu X, Wu Y and Wang J. Effects of fluoride and arsenic on serum thyroid hormones in rats. J Herbal Med Toxic. 2008; 2: 39-43.

5. Cinar A, Selcuk M. Effects of chronic fluorosis on Thyroxine, triiodothyronine and protein-bound iodine in cows. Fluor. 2005; 38: 65-68.

6. Fawell J, Bailey K, Chilton J, Dahi E, Pewtrell L, Magara Y editors. WHO Drinking Water Quality Series, Fluoride in drinking water; 2006 Nov 21, Geneva Switzerland: IWA Publishers London UK; 2006.

7. Fordyce FM, Vrana K, Zhovinsley E, Povoroznuk V, Toth G, Hope BC et al.A health risk assessment for fluoride in Central Europe. Envt Geochem Heal. 2007; 29: 83-102.

8. Teotia SPS, Teotia M. Secondary hyperparathyroidism in patients with endemic skeletal fluorosis. Br Med J. 1973; 1: 637 40.

9. Agalakova NI, Gusev GP. Molecular mechanisms of cytotoxicity and apoptosis induced by inorganic fluoride. ISRN Cell Biology 2012; 1: 1-16.

10. Sawan RM, Leite GA, Saraiva MC, Barbosa F, Tanus-Santos JE, Gevlach RF. Fluoride increases lead concentrations in whole blood and in calcified tissues from lead exposed rats. Toxic. 2010; 271: 221-226.

11. Singh M, Kanwar KC. Effect of fluoride on copper, manganese and zinc in bone and kidney. Bull Envt Contam Toxic. 1981; 26: 428-31.

12. Dawes $\mathrm{C}$. What is the critical $\mathrm{pH}$ and why does a tooth dissolve in acid. J. Can Dent Assoc. 2003; 69: 722-24.

13. Balzar ES, Linder LE, Sund ML, Lonnies H. Effect of fluoride on glucose incorporation and metabolism in biofilm cults of Streptococcus mutans. Eur J Oral Su. 2001; 109: 182-86.

14. Sulton SV, Bender GR, Marques RE. Fluoride inhibition of proton - trans locating AT Pases of oral bacteria. Infect Immun. 1987; 55: 2597-2603.

15. Teotia SPS, Teotia M, Singh KP. Highlights of forty years of research in endemic skeletal fluorosis in India.Proceedings of 4th International Workshop on Fluorosis Prevention and Defluoridation of Water;2004 Mar 2-6; Colombo, Sri Lanka.p107-125.

16. Tamer MN, Koroglu KB, Arslan C. Osteoscleorosis due to endemic fluorosis. Sci Total Envt. 2007; 373: 43-8.

17. Kay CE, Tourangean PC, Gordon CC. Fluoride levels in indigenous animals and plants collected from uncontaminated ecosystems. Fluoride 1975; 8: 125-33.

18. Bezerra de Menezes LM, Volpato MC, Rosalen PL, Curry JA. Bone as a biomarker of acute fluoride toxicity.For Sci Int.2003; 137: 209-214.

19. Shashi A. Biochemical effects of fluoride on thyroid gland during experimental fluorosis. Fluoride 1988; 21: 127-130.

20. McLaren JR. Possible effects of fluoride on the Thyroid. Fluoride 1976; 9: 105-116.

21. Visser JT, Peeters RP. Clinical summary. Proceedings of Annual Meeting of Endocrine Society; 201227 Apr-May 01; Boston Massachusetts USA: 2012; 9(4); 734-43.

22. Pratap D, Singh D. Impact of fluoride on the environment and human health.Int J science, Spirit, Bus Tech. 2013; 1(2): 56-61.

23. Rasmussen DP, Boldt BM, Wilkinson CW, Yellon SM, Matsumoto AM. Daily Melatonin administration at middle age sup- presses male rat visceral fat, plasma leptin and plasma insulin to youthful levels. Endocrin. 1999; 140: 1009-12.

24. Bharti VK, Srivastava RS, Kumar H, Baig S, Majumdar AC, Singh $\mathrm{G}$ et al. Effects of Melatonin and Epiphyseal Proteins on Fluoride - Induced Adverse Changes in Antioxidantstatus of Heart, Liver and Kidney of Rats. Adv Pharmac Sci [Internet] 2014 Mar 26 [cited 2017 Dec 01]; Available from: https://doi. org/10.1155/2014/532969

25. National Research Council.Fluoride in drinking water.A scientific review of EPA's standards.2006 Mar. Washington DC National Academies Press US; 2006 [Internet] Available from: https://doi.org/10.17226/11571 [Accessed on 09.11.2020].

26. Anticaries drug products for over the counter human use. Code of Federal Regulations 21 CFR Part 355. 1999 Mar 01; 282-85.

27. Varadacharijulu NC, Rao PR. Gluconeogenesis and glycogenolysis in fluoride-treated rats. Indian J. Exp. Biol 1997; 35: 906908.

28. Qin J, Chai G, Brewer JM, Lovelace LL, Lebioda L. Fluoride inhibition of Enolase: crystal structure and thermodynamics. Biochemistry 2006; 45: 793-800.

29. Prystupa J. An NRC and AT SDR based review of safety standards for exposure to fluorine and fluorides. Toxicology Mechanisms and MethodsFluorine2011; 21: 103-70.

30. Banupriya CAY, Anita K, Muralimohan E, Pillai KS, Murthy PB. Toxicity of fluoride to diabetic rats.Fluoride. 1997; 30: 4350.

31. Rigalli A, Ballina JC, Puche RC. Bone mass increase and glucose tolerance in rats chronically treated with sodium fluoride. Bone Miner 1992; 16: 101-108.

32. Yu Y, Yang W, Dong Z, Wan C, Zhang J, Liu J et al. Neurotransmitter and receptor changes in the brain of fetuses from areas of endemic fluorosis. Fluor. 2008; 41: 134-38.

33. Uyghurturk DA, Goin DS, Den Besten PK. Maternal and Foetal exposure to Fluoride during mid-gestation among pregnant women in Northern California. Envt Health. 2020; 19 (38): 1- 22

34. Pawar AC, Naik JK, AnithaKumari S. Cytogenetic analysis of Human Lymphocytes of Fluorosis affected men from Endemic Fluorosis region in Nalgonda District of Andhra Pradesh. Fluoride 2014; 47 (1): 78-84.

35. Shivaprakash PK, Ohri K, Noorani H. Relation between dental fluorosis and intelligence quotient in school children of Bagalkot district. J. Indian SocPedodPrev Dent 2011; 29: 117-20.

36. Choi AL, Sun G, Zhang Y, Grandjean P. Developmental fluoride neurotoxicity; a systematic review and meta-analysis. Environ Health Perspect 2012; 120: 1362-68.

37. Cao K, Xiang J, Dong YT, Xu Y, Li Y, Song H et al. Exposure to Fluoride aggravates the impairment in learning and memory and Neuropathological lesions in mice carrying the APP/PSI double transgenic mutation. Alzheimer's Res Ther. [Internet]. 2019 Apr [cited 2020 Jan 30]; 11(35): Available from :https:// doi.org/10.1186/s13195-012-0490-3.

38. Ortez - Perez D, Rodriguez - Martinez M, Martinez F, Borja Aburto VH, Castelo J. Fluoride induced disruption of reproductive hormones. Environ Res. 2003; 93: 20-30.

39. Tokar V, Savchenko ON. Effect of inorganic fluorine compounds on the functional state of the pituitary testis system.Probi.Endokinol1977; 23: 104-07.

40. Jiang CX, Fan QT, Cheng XM, Cui LX. Relationship between spermatogenic cell apoptosis and serum estradiol level in rats exposed to fluoride. Wei Sheng Yan Jiu. 2005; 34: 32-4.

41. Ando S, Sirrianni R, Forastieri P, Casaburi I, Lanzino M. Aromatic expression in prepubertal Sertoli cells: effect of thyroid hormone. Mol cell Endoc. 2001; 178: 11-21. 
42. Pezzi V, Panno ML, Sirianni R, Forastieri P, Casaburi I. Effect of tri-iodothyronine or alternative splicing events in the coding region of cytochrome $\mathrm{P} 450$ aromatase in immature rat Sertoli cells. J Endocrinol 2001; 170: 381-393.

43. Eren E, Ozturk M, Mumcu EF, Canatan D. Fluorosis and its haematological effects. Toxicol and Health 2009; 21(10): 255-8.

44. Susheela AK, Toteja GS. Prevention and control of fluorosis and linked disorders: Developments in $21^{\text {st }}$ century - Reaching out to patients in the community and hospital settings for recovery. Indian Journal of Medical Research2018; 148: 539-47.

45. Jha SK, Mishra VK, Sharma DK, Damodaran T. Fluoride in the environment and its metabolism in humans. Rev Envt Contam Toxic. 2011; 211: 121-42.

46. Ranjan R, Ranjan A. Fluoride toxicity in animals. In: Toxic effects: New York: Springer Publications;2015.35-51. Available from https://doi.org/10.1007/978-3-319-17512-6 [Accessed on 09.11.2020].

47. Akuy S, Yarat A, Alturfan EE, Kaya S. Fluoride in saliva and its impact on health.In:Preedy VR, editor. Fluorine London: Royal Soc Chem. 2015. 173- 85.

48. Ozsvath DL. Fluoride and environmental health: a review. Rev. Environ Sci Bio Technol. 2009; 8: 59-79.

49. Valdez - Jimenez L, Fregozi CS, Beltran MM, Coronado OG, Vega MP. Effects of fluoride on the Central Nervous system. Neurologia. 2011; 26: 297-300.

50. Freni SC. Exposure to high fluoride concentrations in drinking water is associated with decreased birth rates. J Toxic Envt Health. 1994; 42: 109 - 121.

51. Stannard JG, Shim YS, Kritsineli M, Labropoulou P, Tsmatsouris A. Fluoride levels and fluoride contamination of fruit juices. J Clinical Pediatric Dent. 1991; 16 (1): 38- 40.
52. Liu Y, Tellez Rojo M, Hu H, Sanchez BN, Martinez-Mier EA, Basu $\mathrm{N}$ et al. Fluoride exposure and pubertal development in children living in Mexico City.Environmental Health [Internet].2019 Mar 29 [cited 2019 Aug]; 18(26):Available from: https://doi.org/10.1180/s12940-019-04657

53. Lakhan SE, Kirchgessner A, Hofer M. Inflammatory mechanisms in ischemic stroke: Therapeutic approaches. J. Translational Med. 2009: 17(7): 97.

54. Profumo E, Button B, Rigano R. Oxidative stress in cardiovascular inflammation: Its involvement in autoimmune responses. Int. J. Inflam [Internet]. 2011 Jun 28 [cited 2014 Apr 11];Available from:https://doi.org/10.4061/2011/295705

55. Pain G. Fluoride causes Heart disease, Stroke and Sudden Death. Exposing corruption in the Fluoridation Industry [Internet].2016 Sep 09 [cited 2017 Jan 10]; Available from: https:// doi.org/10.13140/RG.2.1.3973.88647

56. Zhou QH, Zhang DC.Electrocardiogram analysis of 271 dental Fluorosis cases. Chen J Epidemiol. 1988; 5: 296-7.

57. Karademir S, Akcam M, Kuyubulu AE, Olgar S, Oktem F. Effects of Fluorosis on QT dispersion, Heart rate variability and Echocardiographic parameters in Children. Anatolian Journal of Cardiology 2011; 11: 150-5.

58. Saxena HN, Mehta Y, Trehan N. Anaesthesia and fluorosis. Anaesthesia 1999; 54: 96-7.

59. Rao M, Menon K. Anaesthetic management for cervical laminectomy in patients of skeletal fluorosis. J Anaesthesiol Clin Pharmacol.1987; 3: 207-10.

60. Reddy DR. Neurology of endemic Skeletal Fluorosis. Neurology Ind. 2009; 57(1): 7-12. 